Western University

Scholarship@Western

7-2019

Chromium: Rise and Shine in Peritoneal Dialysis Patients?

Guido Filler

Christopher Mclntyre

Follow this and additional works at: https://ir.lib.uwo.ca/paedpub

Part of the Pediatrics Commons 


\title{
CHROMIUM: RISE AND SHINE IN PERITONEAL DIALYSIS PATIENTS?
}

\author{
Guido Filler, ${ }^{1,2,3,4 *}$ and Christopher McIntyre ${ }^{1,2,4}$ \\ Department of Paediatrics, ${ }^{1}$ Schulich School of Medicine \& Dentistry, Western University, London, ON, Canada; \\ Department of Medicine, ${ }^{2}$ Division of Nephrology, Schulich School of Medicine \& Dentistry, Western University, \\ London, ON, Canada; Department of Pathology \& Laboratory Medicine, ${ }^{3}$ Schulich School of Medicine \\ \& Dentistry, Western University, London, ON, Canada; Lilibeth Caberto Kidney Clinical \\ Research Unit, ${ }^{4}$ London Health Sciences Centre, London, ON, Canada
}

\begin{abstract}
Some trace elements are altered with chronic kidney disease. Selenium, zinc, and manganese tend to be wasted, and there is growing evidence that selenium deficiency is associated with mortality on dialysis. Other trace elements accumulate, such as chromium, cobalt, lead, molybdenum, and vanadium. The highest chromium levels are found in dialysis patients. The dialysis modality may further affect these levels, especially in hemodialysis patients, where even small contaminations in the dialysis feed water may lead to a concentration gradient that increases the concentration of certain trace elements. Chromium levels in peritoneal dialysis (PD) patients have been understudied. A single cross-sectional study found substantially higher chromium levels in PD patients. In that study, the chromium concentration in the spent dialysate decreased substantially, suggesting that PD fluid could be a source of chromium. Chromium-lactate complexes may have been formed, which are easily absorbed. In our center, we observed a decrease in chromium level when using physiological PD fluids. This review discusses the potential mechanisms and raises the question of whether this accumulation of chromium is unlikely to be associated with a beneficial outcome.
\end{abstract}

Perit Dial Int 2019; 39(4):320-322

https://doi.org/10.3747/pdi.2019.00013

KEY WORDS: Hemodialysis; trace elements

Chromium ( $\mathrm{Cr}$, atomic number 24$)$ is well known as an additive for steel alloys to create shiny metals and to prevent rusting. Metallic $\mathrm{Cr}$ does not occur in nature but is found in compounds, in a variety of valence states (1-2). Sources of exposure in humans include air, food, and water, with food and especially water being the main sources $(2,3)$. Chromium concentrations in drinking water may be highly variable (4). Hexavalent $\mathrm{Cr}$ easily enters cells through facilitated uptake, and its reduction from $\mathrm{Cr}$ (VI) to $\mathrm{Cr}$ (III) creates free radicals (2). It is distributed to, and accumulated by, the erythrocyte

Correspondence to: Guido Filler, University of Western Ontario, Paediatric Nephrology, Children's Hospital, London Health Sciences Centre, 800 Commissioners Road East, Rm B1-135, London, 0N, N6A 5W9 Canada.

guido.filler@lhsc.on.ca

Received 11 January 2019; accepted 23 February 2019. while the highest concentrations of $\mathrm{Cr}$ are found in the kidney and liver. Chromium is highly protein-bound and is slowly excreted via the kidneys, by tubular secretion (4). Chromium is carcinogenic, as inhalation has been shown to cause lung cancer in humans, and exposure has been shown to cause tumors in the stomach, intestinal tract, and lung in animals (2). Depending on the route of exposure, trivalent and hexavalent $\mathrm{Cr}$ are also associated with gastrointestinal, immunological, hematological (such as anemia), reproductive, and developmental potentially devastating effects (4). While accumulation of $\mathrm{Cr}$ occurs in earlier states of chronic kidney disease (CKD) (4), Tonelli et al. have recently reported that $\mathrm{Cr}$ accumulates substantially in hemodialysis (HD) patients $(5,6)$. This association was confirmed by measuring trace elements in the hair of adult HD patients (7). Chromium also accumulates substantially in bone of dialysis patients (8). Data from peritoneal dialysis (PD) patients have been scant.

In that context we are delighted to see a recent study of 169 chronic dialysis patients from 3 Israeli centers in this edition of Peritoneal Dialysis International, which included $21 \mathrm{PD}$ patients. The median (interquartile range) serum $\mathrm{Cr}$ level was significantly higher in patients treated with PD than in patients treated with HD: $5.00(3.24-6.15)$ versus $1.83(1.29-2.45) \mu \mathrm{g} / \mathrm{L}, p<0.001$. The association with PD became even stronger when using a multivariate regression model, with an odds ratio (OR) of 11.87 (95\% confidence interval [CI] 2.85-49.52, $p=0.001$ ). These findings remained significant after adjusting for age, gender, diabetes status, smoking, dialysis vintage, use of diuretics, and residual renal function (9). As all the patients came from the same area and had the same access to municipal drinking water, the authors did not adjust for the water $\mathrm{Cr}$ content (also assumed that mains rather than purchased bottled water was the main source of hydration). They checked the HD water for $\mathrm{Cr}$ and it was found to be below the American Association for Advancement of Medical Instrumentation (AAMI) standards. A particular strength of the study is the additional measurement of $\mathrm{Cr}$ in fresh and spent PD solutions, though only in 5 of the patients. Perhaps the most striking finding was the fact that the $\mathrm{Cr}$ concentration in the PD solutions decreased with treatment 
$(1.23[0.76-1.45] \mu \mathrm{g} / \mathrm{L}$ in fresh and $0.25[0.22-0.44] \mu \mathrm{g} / \mathrm{L}$ in spent solution), suggesting that PD fluid per se is a potential source for $\mathrm{Cr}$. As elegantly discussed by the authors, $\mathrm{Cr}$ forms a Cr-lactate complex which is easily absorbed. It is unclear if more physiologic PD solutions such as Physioneal (Baxter Healthcare Corporation, Deerfield, IL, USA) or BicaVera (Fresenius Medical Care, Bad Homburg, Germany), in which lactate exposure is reduced/absent, would be more favorable from the point of view of $\mathrm{Cr}$ presentation for peritoneal absorption. One of the major limitations of the study is its lack of water and food $\mathrm{Cr}$ content assessment. The study also did not correlate data such as erythrocyte stimulating agent needs with $\mathrm{Cr}$ levels or any of the multiple side effects listed below. The authors conclude that the study adds to the present knowledge by demonstrating that $\mathrm{Cr}$ concentrations are higher in PD patients, and the results of the 5 patients suggests that the PD fluid was a significant source of $\mathrm{Cr}$. The authors call for more longitudinal studies and indeed the measurement of exposure at a single time point does not allow the time/exposure element of the risk to be appreciated. The cross-sectional nature of this assessment also means that batch contamination of PD fluid (all supplied from a single facility) cannot be ruled out, injecting a little caution into interpretation of these data necessarily being indicative of innate differences between dialysis modalities.

For studies measuring metal ion levels such as $\mathrm{Cr}$, an important consideration is the valency (electron charge) of these ions. This is especially important with $\mathrm{Cr}$, since it is well established that the $\mathrm{Cr}$ (VI) ion can easily enter cells and is associated with oxidative stress due to the reduction to $\mathrm{Cr}$ (III) in vivo (10). In contrast, the more commonly found $\mathrm{Cr}$ (III) ion is much less dangerous or may actually be beneficial (10). Chromium (VI) ion is more carcinogenic and cytotoxic than the $\mathrm{Cr}$ (III) ion (10). It is also unclear what $\mathrm{Cr}$ levels are safe. Most laboratories also do not test the $\mathrm{Cr}$ valency. In fact, chromium lactate is used in nutritional supplements as a source of chromium (11). In some long-term studies, investigators assume that $\mathrm{Cr}$ (VI) is reduced immediately to $\mathrm{Cr}$ (III), since this happens rapidly ex vivo, but this remains unproven. The study by Feldman et al. (10) did not measure the valency of $\mathrm{Cr}$.

It is also unclear whether these high $\mathrm{Cr}$ levels are harmful. With oral exposure, $\mathrm{Cr}$ has been linked to the following, although there is little or no information about the valency $(4,12)$ :

- Death and, at lethal doses, respiratory effects such as pleural effusion, pulmonary edema, bronchitis, and bronchopneumonia.

- Cardiovascular effects such as cardiopulmonary arrest, and a drop in cardiac output, heart rate, and blood pressure.

- Lung cancer.

- Gastrointestinal effects from $\mathrm{Cr}$ in drinking water such as oral ulcer, diarrhea, abdominal pain, indigestion, and vomiting.

- Musculoskeletal effects such as rhabdomyolysis.

- Hematological effects including leukocytosis and immature neutrophils.

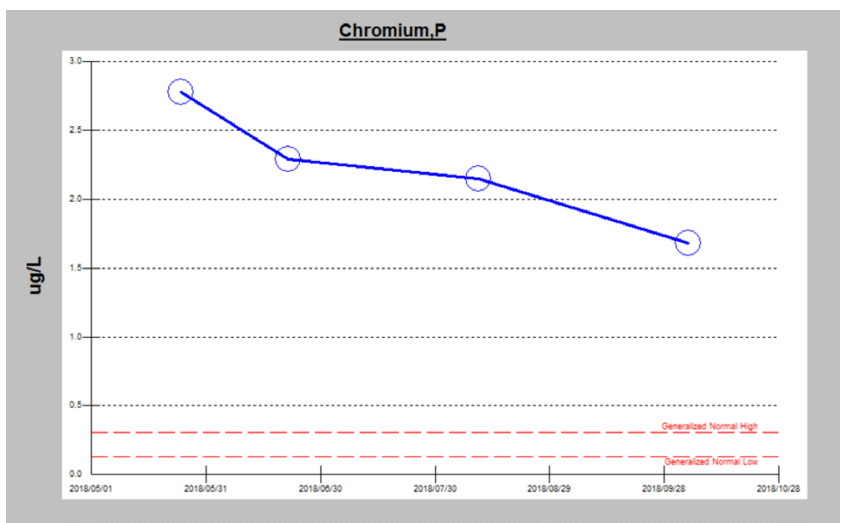

Figure 1 - Chromium levels in a child who was converted from HD to PD using high-dose CCPD with Physioneal. $H D=$ hemodialysis; $P D=$ peritoneal dialysis; CCPD = continuous cycling PD.

- Hepatic effects such as the development of jaundice, and increased bilirubin, serum lactic dehydrogenase, alanine and aspartate aminotransferase, and $\gamma$-glutamyl transferase.

- Direct renal effects such as renal failure characterized by proteinuria, hematuria and anuria, necrosis of renal tubules, oliguria, and destruction of the tubular epithelium of the kidneys.

- Chromium supplementation has also been associated with weight loss.

Many, but not all of these Cr-related issues, are observed in renal patients. Associations also do not infer causality. In Tonelli's study, death and cardiovascular risk were associated with essential trace element deficiencies, but not with Cr elevation $(5,6)$. Nonetheless, this accumulation of $\mathrm{Cr}$ is unlikely to elicit a beneficial adaptive response. What should be done about his accumulation of $\mathrm{Cr}$ in PD patients? Based on the data provided, absorption of $\mathrm{Cr}$ from the dialysate clearly is a possibility. If so, we need to compare the findings with those in patients who are being treated with physiologic solutions. If $\mathrm{Cr}$ concentrations do not decrease in the spent fluid, this may be a powerful argument for the use of these solutions. In 1 of our patients on long-term PD (13) we noticed a slow steady decline of her $\mathrm{Cr}$ levels after converting her from HD to PD exclusively using biocompatible bicarbonate-containing low-lactate PD solutions (Figure 1). Concurrently, her lactate dehydrogenase (LD) gradually dropped from $253 \mathrm{U} / \mathrm{L}$ to $216 \mathrm{U} / \mathrm{L}$ (normal $<300 \mathrm{U} / \mathrm{L}$ ) and the alkaline phosphatase dropped from $405 \mathrm{U} / \mathrm{L}$ to $251 \mathrm{U} / \mathrm{L}$ (normal range $129-417 \mathrm{U} / \mathrm{L}$ ). Clearly this is anecdotal, but it is highly consistent with the above concepts of the pathophysiology of $\mathrm{Cr}$ accumulation in $\mathrm{PD}$ patients.

\section{CONCLUSIONS}

We congratulate Leonid Feldman and the team on their study and hope to soon learn more about the impact of elevated $\mathrm{Cr}$ levels in CKD, especially in PD patients. As Tonelli et al. (5) have clearly shown, trace element derangements in dialysis patients affect outcomes, and perhaps it is prime time to start monitoring these in our dialysis patients. We also 
need to establish safe levels in order to assess toxicity. This could potentially be done by linking cancer data of PD and HD patients to levels.

\section{DISCLOSURES}

The authors have no financial conflicts of interest to declare.

\section{REFERENCES}

1. Barceloux DG. Vanadium. J Toxicol Clin Toxicol 1999; 37(2):265-78.

2. US Department of Health and Human Services. Toxicological profile for chromium. United States: United States Government; September 2012 [Available from: http://www.atsdr.cdc.gov/ToxProfiles/tp58.pdf].

3. US Department of Health and Human Services. Toxicological profile for vanadium. United States: United States Government; September 2012. [Online.] Available at: http://www.atsdr.cdc.gov/ToxProfiles/tp58.pdf.

4. Filler G, Kobrzynski M, Sidhu HK, Belostotsky V, Huang SS, McIntyre C, et al. A cross-sectional study measuring vanadium and chromium levels in paediatric patients with CKD. BMJ Open 2017; 7(5):e014821.

5. Tonelli M, Wiebe N, Bello A, Field CJ, Gill JS, Hemmelgarn BR, et al. Concentrations of trace elements and clinical outcomes in hemodialysis patients: a prospective cohort study. Clin J Am Soc Nephrol 2018; 13(6):907-15.

6. Tonelli M, Wiebe N, Bello A, Field CJ, Gill JS, Hemmelgarn BR, et al. Concentrations of trace elements in hemodialysis patients: a prospective cohort study. Am J Kidney Dis 2017; 70(5):696-704.

7. Ochi A, Ishimura E, Tsujimoto Y, Kakiya R, Tabata T, Mori K, et al. Trace elements in the hair of hemodialysis patients. Biol Trace Elem Res 2011; 143(2):825-34.

8. D'Haese PC, Couttenye MM, Lamberts LV, Elseviers MM, Goodman WG, Schrooten I, et al. Aluminum, iron, lead, cadmium, copper, zinc, chromium, magnesium, strontium, and calcium content in bone of end-stage renal failure patients. Clin Chem 1999; 45(9):1548-56.

9. Feldman L, Beberashvili I, Abu Hamad R, Yakov-Hai I, Abramaov E, Wasser $W$, et al. Serum chromium levels are higher in peritoneal dialysis than in hemodialysis patients. Perit Dial Int 2019; 39:330-4.

10. Jomova K, Valko M. Advances in metal-induced oxidative stress and human disease. Toxicology 2011; 283(2-3):65-87.

11. Hininger I, Benaraba R, Osman M, Faure H, Marie Roussel A, Anderson RA. Safety of trivalent chromium complexes: no evidence for DNA damage in human HaCaT keratinocytes. Free Radic Biol Med 2007; 42(12):1759-65.

12. Filler G, Felder S. Trace elements in dialysis. Pediatr Nephrol 2014; 29(8):1329-35.

13. Derynck MR, Jones S, Rachinsky IV, McIntyre CW, Blake P, Filler G. Successful reintroduction of peritoneal dialysis after peritoneal-pericardial fistula in a child: a case report. Perit Dial Int 2018; 38(2):154-6. 